http://doi.org/10.35784/iapgos.2577

\title{
DEVELOPING SOLUTION FOR USING ARTIFICIAL INTELLIGENCE TO OBTAIN MORE ACCURATE RESULTS OF THE BASIC PARAMETERS OF RADIO SIGNAL PROPAGATION
}

\author{
Andrii Shchepak, Volodimir Parkhomenko, Vyacheslav Parkhomenko \\ State University of Telecommunications, Kiev, Ukraine
}

Abstract. The article considers the methods of calculating radio signal power. The main factors influencing the distribution and their connection with the error in the calculations of the indicators' peak values are analyzed. The regularities of signal propagation and the correlation between the distance from the radio signal source and the ratio of noise to useful information are determined. These patterns allow us to develop a model of artificial intelligence, which improves the prediction of results compared to existing calculation methods. The obtained results present the efficiency of the offered method.

Keywords: artificial intelligence, cellular neural networks

\section{OPRACOWANIE METODY WYKORZYSTANIA SZTUCZNEJ INTELIGENCJI DO UZYSKIWANIA DOKŁADNIEJSZYCH WYNIKÓW PODSTAWOWYCH PARAMETRÓW PROPAGACJI SYGNALÓW RADIOWYCH}

\begin{abstract}
Streszczenie. Rozważono metody obliczania mocy sygnału radiowego. Przeanalizowano wplyw głównych czynników na rozkład i ich zwiazek z błędem $w$ obliczeniach wartości szczytowych wskaźników. Wyznaczono zależności na propagację sygnału i korelację między odległościa od źródła sygnału radiowego a stosunkiem szumu do informacji użytecznej. Zależności te pozwalaja na opracowanie modelu sztucznej inteligencji, który poprawia predykcje wyników w porównaniu z dotychczasowymi metodami obliczeń. Uzyskane wyniki pozwalają wnioskować o skuteczności oferowanej metody.
\end{abstract}

Słowa kluczowe: sztuczna inteligencja, komórkowe sieci neuronowe

\section{Introduction}

One of the important tasks in modern radio electronics is to describe the transmission of radio waves to calculate the radiation coverage area and the quality of information exchange. The paper proposes to explore the usage of AI to generate more accurate results based on a limited amount of input data.

One of the most common ways to calculate the coverage of radio waves is to measure the input data in all necessary points. Despite all the advantages of this method, it has several significant disadvantages that in certain conditions make it impossible to use, primarily the price and the impossibility of measuring due to the unavailability of a certain area. As a replacement for this and other methods, it is proposed to consider the use of artificial intelligence and a limited amount of existing data.

\section{Standard options for calculating the transmission of the radio signal}

To study the features of the method, a conditional location of objects is proposed. For example, at point $\mathrm{E}$ is the only source of propagation of radio signals. Between A-E there is a source of deterioration of the radio signal transmission, but there is no additional data on its effect on the radio signal. Despite the existence of methods for estimating signal strength after the passage of static structures, in a limited number of measurements it is impossible to obtain the results of calculations of sufficient accuracy [4]. The gaps EB and BD are of equal length. Measurements such as altitude and radio signal strength are performed at the tops of these intervals.

Figure 1 shows the schematic location of the transmitter and measuring points of signal power and receiver height above sea level. Based on neither this information, it is proposed to calculate the data on the associated area.

The ABCD figure creates a structure that can be considered as a separate cell. Given the presence of measurements only on the vertices of the figures, an important task in calculating the propagation of the radio signal is to predict its parameters at each point. In addition to the fact that it is not possible to take into account all the extremum points on the plane in the absence of additional data, it is possible to obtain satisfactory accuracy of calculations.

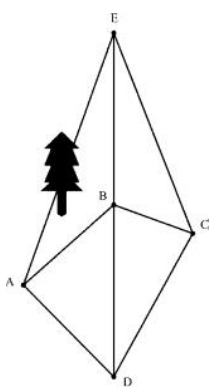

Fig. 1. Location of conditional objects

At the initial calculation of the transmission of radio waves uses software Atoll 3.1.2, which allows you to get results for all basic models with the ability to change them and the basic parameters for them. However, this, as well as other software, has a significant disadvantage - the lack of quality topographic maps for the territory of Ukraine, which ultimately has a negative impact on the quality of calculation results. The calculation data for the test environment are indicated on the graph under number.

Known methods of calculation allow to obtain the result on such parameters as the power of the radio signal with a sufficient amount of input data, but without taking into account the heterogeneity of the conditions of signal transmission in certain parts of the path.

\section{Prerequisites for using AI for calculations}

There are several ways to solve the problem of insufficient quantity and/or quality of input data.

Forecasting should be based on two methods:

- calculation of input data based on already known measurement results from neighboring points

- calculation of information in adjacent paths with available information about the signal quality at a certain point

Each of these methods has advantages and disadvantages. The first method allows to obtain approximate results in the spatial area in the presence of at least four points, by dividing the group of all measurement sites into cells with the union of every four adjacent points, provided that two adjacent sides of the cell do not intersect. Modern computer technology is able to quickly process 
large amounts of information, so such calculations can be performed almost without delay, which is an important condition for moving points of reception/transmission. However, there are significant disadvantages - first, the calculations show low accuracy in the case of rapid or point change of conditions Secondly, the quality of the results in the composition of the cell strongly depends on the quality of measurements at each of its vertices.

The second method allows you to calculate the average value of the parameters on the entire line between the transmitter and the point where the data of signal quality and other measurements. Among the disadvantages of this method is that the generated values do not take into account peaks and abrupt changes, but reflect only close to the average value. This approach is better than the first method in many cases in which such calculations are used. Using data based on the calculation of the average value is incorrect, so for the Earth's surface is needed to select data based on the binding to WGS 1984. The method also demonstrates different accuracy between the transmitter and the measuring point, and between the measuring point and beyond The advantages include, firstly, the increase in the quality of measurements due to the obtained measurement results at the intermediate point. Secondly, although the obtained data do not show high accuracy in the value of signal quality at each point of the measurement interval on the segment, but allow you to accurately set the highs and lows of both signal quality and peak values of its change in real time.

To minimize the negative aspects of both methods and achieve maximum results, it is proposed to use a combination of these two methods, which is possible due to the fact that most measurements can be used for both methods. An example of the best input conditions is when two opposite cell vertices are on the same line from the transmitter, and the distance between the transmitter and the nearest vertex is equal to the distance between it and the vertex that has no direct connection with it. Among the main measurements are those that are required to achieve a high level of calculation accuracy: the height at which the receiver is located; soil height above sea level; the presence of harmful radiation at the point of measurement; the presence of large static structures or trees.

\subsection{Options for using AI to calculate radio signal propagation}

To obtain the results of information processing, it is proposed to build a learning model. "Supervised learning" is used to prepare the model, as the data entered must be prepared and marked in advance. Python programming language tools and Tensorflow, Keras and Pandas libraries are used to create the model.

At the first stage of the project, only the height of the soil above sea level is used. This parameter is important for further model development, as an important step will be to create a model to identify interference based on topographic data or a satellite image of the surface. Therefore, with sufficient accuracy to determine the altitude, it can be used as a basis for further calculation of the total altitude, taking into account the possible presence of stationary objects and / or trees that impair the patency of the radio signal or the reliability of the information transmission along the entire length of the path [6].

Figure 2 shows the data obtained when calculating the power of the radio signal by the formula without information from the intermediate point, and calculations of data in the presence of information from the intermediate point, as well as using the AI model.

The legend of the graph under number 3 shows the results of the calculation of the radio signal power without taking into account the data from the intermediate point. This leads to the fact that all values are average without taking into account the oscillations and deviations that occurred due to different properties of the environment during the passage of the radio signal.

The legend of the graph under numbers $1-2$ demonstrates the results of calculations in the case of results from an intermediate point. In case 1 , in contrast to case 2 , the processing of calculation results by the basic AI model or few models in a row is additionally used [3].

The initial number of 100 positive and negative examples with good quality with known results of signal strength measurements were used to teach the model. The result of data processing on the test information is an improvement in the calculation of the radio signal power level compared to the situation when AI models are not used. The most accurate and reliable indicators of calculation are shown by the multilevel model of AI that allows to create the most exact network forecasting at the design stage.

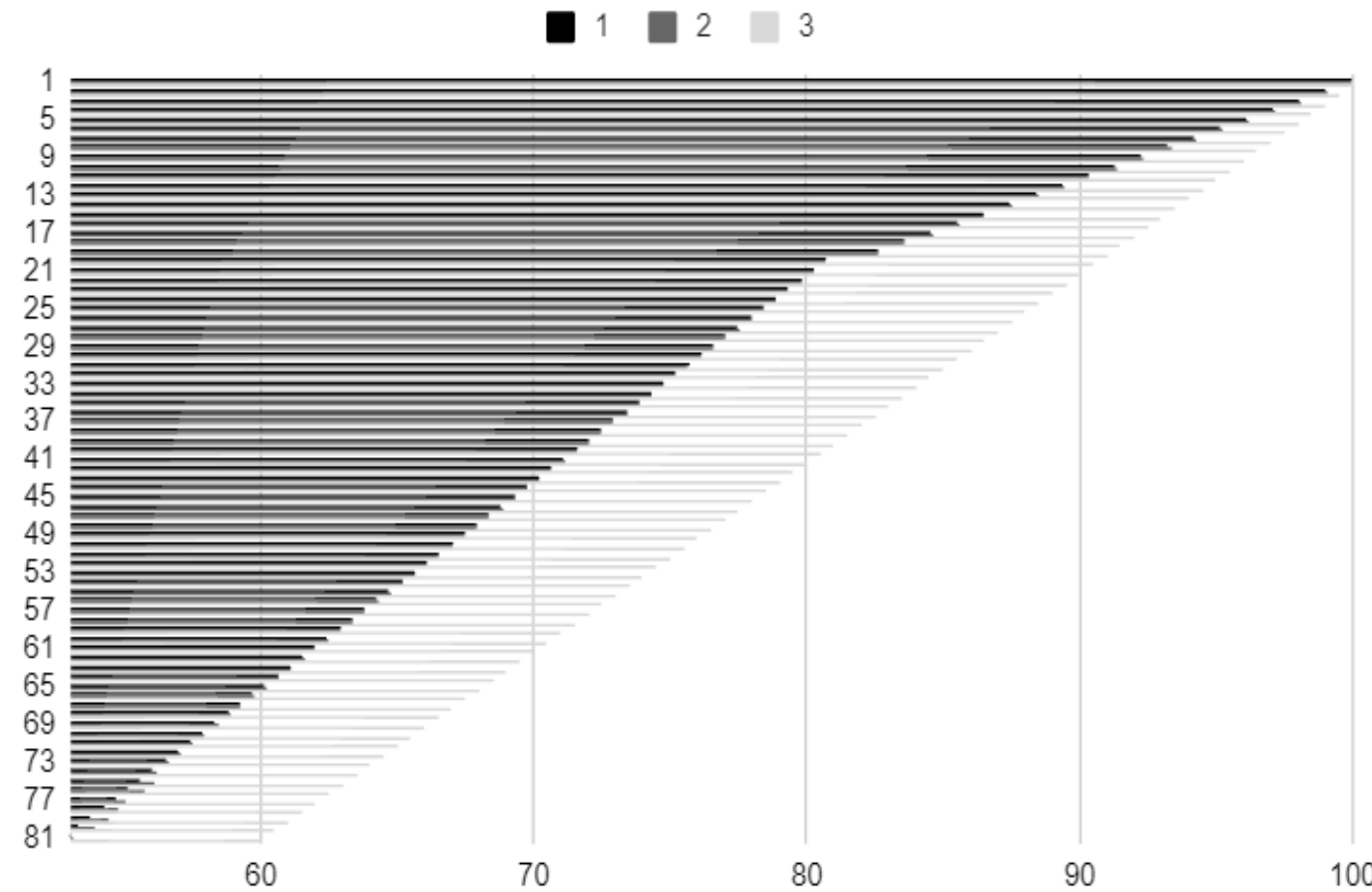

Fig. 2. Dependence of the results of calculations of radio signal power at a distance from the transmitter in relation to the maximum (100\%) with three different methods of calculation with the same input data 


\subsection{Changes, which can be achieved by using the proposed technology}

The difference between the normal calculation and the calculation using the model that was learned from the test data is shown in figure 3 .

The difference in absolute terms is not significant, because the formula for calculating the power of the radio signal is quite accurate. However, this difference is significant and obvious in relative terms. Taking into account the results obtained when designing radio networks will in the future improve the transmission of radio signals, avoid the negative effects that occur during miscalculations, as well as increase the coverage area of the network.

It is also advisable to investigate the reasons why the difference between the calculated and predicted level differs the more, the greater the distance traveled by the signal from the transmitter to the place of analysis. First, it is obvious that with decreasing signal power, the increase in the ratio of the noise level to the level of useful information occurs faster, than in the start of the line.

It is important to understand that the more training cycles the model goes through and the more input data is taken into account, the more accurate the indicators will be. This is achieved due to the fact that the model replaces the mechanism of approximation of the function of calculating indicators with an extremely large number of auxiliary functions, which would not be possible without the use of such a method.

Another, more important reason is the existence of the Fresnel zones. If there is an object within a particular Fresnel zone, part of the initial signal that does not move in the direction of the antenna, and will propagate in some other direction in space, may be partially reflected from the object and fall to the receiving antenna. This reflected signal can lead to constructive or destructive interference on the receiver, depending on the path length and phase shift angle, which will result in the receiver reflected wave. The greater the distance between the transmitter and receiver, the larger the diameter of this zone, and hence the effect on the signal transmission of any object that may fall into this zone. For example, for a distance of $2.8 \mathrm{~km}$, the radius of the zone can be 7.8 meters [1]. At a time when it is difficult to take such risks into account when calculating according to the formula, the use of AI models allows to significantly change the final result of calculations.

If the calculation of the diameter of the Fresnel zones is entered as an additional input indicator, it will definitely have a positive effect on the quality and accuracy of the data. However, a large amount of input data increases the learning time of the model and processing of the finished model of input indicators, and can also lead to a phenomenon known as the formation of harmful dependencies, which will ultimately reduce the quality and usefulness of the result [2]

The obtained data can be used in the calculation of the area of the radio signal. Improving the accuracy of calculating the signal power levels at the vertices of the cell will have a positive effect on the calculation of information at each of its points. Obtaining more complete and accurate data at the design stage of the network will calculate the required equipment without unnecessary information redundancy, while maximizing the reliability of message delivery and speed of information transmission, wich will help to avoid communication losses and other negative phenomena.

Important data in the design for the calculation of network coverage are the height of the transmitter, receiver above sea level, the power level of the useful signal, the presence of other signals in the area of the receiver. Taking these parameters into account when building the model, it will be possible to increase the accuracy and reliability of radio or mobile network forecasting at the design stage.

\subsection{Future directions of research on the basis of the received data}

A promising technology that needs to be implemented in the next stage is the recognition of satellite imagery, followed by the study of important indicators that affect the level of signal transmission by the radio path. One example of such recognition is the determination of the presence of greenery to take into account their impact on the power of the radio signal from transmitter to receiver.

In order to take into account the satellite image data in the analysis of the results, it is necessary to use separate models - one for recognizing geodata from the earth image, and the other for use in predicting the calculated information in the form of interference throughout the signal propagation. The most important task, in this case, is to determine the presence of buildings, tall trees and other static obstacles in the entire plane of the cell. Another important part is the calculation of altitude at each point, because even in the absence of static interference, the signal can be degraded by sudden changes in soil height. It also allows you to calculate the minimum height at which the receiver will be located.

This technology is promising and will allow you to build a map of coverage and radio signal distribution based on a limited amount of data, while showing high accuracy of prediction. The presence of satellite images can be replaced by images of the Earth's surface from the camera in live mode, which will allow you to calculate the generation of radio coverage of surface without delay.
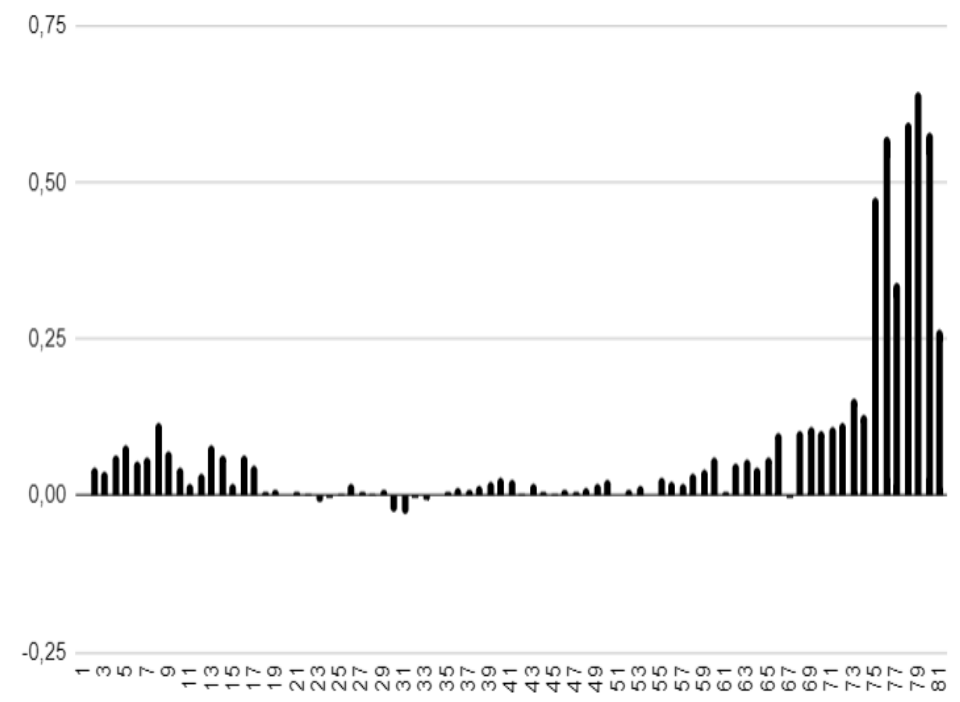


\section{Conclusions}

The article considers a promising technology of using AI for post-processing of input data on radio signal propagation. With the help of the trained model the level of power of a radio signal which can be received by the receiver at a certain distance from the transmitter is predicted. The use of this method together with standard calculations allows to increase the accuracy of the original data, thereby improving the final result at the stage of design and active use of the radio network or a single radio path. The results obtained in relative terms improve quality of forecasting required indicators.

Future tools for further development of the use of AI technology in the design of radio networks were also proposed. If this tool is successfully developed, it will be possible to process real-time data obtained in limited quantities, as well as images of the Earth obtained with a camera from a moving object (e.g. aircraft), and on the basis of this information to analyze the radio network.

The quality of the obtained result directly depends on the number of processed examples, but the model that has already been trained can be reused any number of times and on a variable medium, which makes it possible to analyze the environment in live mode. However, the resource requirements of the system required for data processing are not significant, and therefore the possibility of widespread use of this technology is available and may be recommended for industries such as radio network design, geodata calculation, transport network and transmission line design to avoid their negative impact.

\section{References}

[1] en.wikipedia.org/wiki/Fresnel zone (available: 27.02.2021).

[2] en.wikipedia.org/wiki/Overfitting (available: 27.02 .2021 ).

[3] Gafarov F. M., Halymanov A. F.: Artificial neural networks and thei appendices. Kazan University Press, Kazan 2018.

[4] Miura Y., Oda Y., Taka T.: Outdoor-to indoor propagation modelling with the identification of path passing through wall openings. IEEE 13th PIMRC 1/2002, 130-134.

[5] Parkhomenko V. L.: Basics of television and radio broadcasting. State University of Telecommunications, Kyiv 2017.

[6] Rudoy G. I: The Choice of the Activation Function in the Prediction of Neura Networks. Journal of Machine Learning and Data Analysis 1(1)/2011, 16-39 [http://jmlda.org/papers/doc/2011/no1/Rudoy2011Selection.pdf]
M.Sc. Andrii Shchepak

e-mail:k17pine@gmail.com

Graduate student of State University of Telecommunications, Kyiv, Ukraine. Research interests: telecommunications. Publications: about 3 scientific publications.

http://orcid.org/0000-0002-6570-1129

Ph.D. Volodimir Parkhomenko

e-mail: Volodymyr.P46@gmail.com

Candidate of Technical Sciences, Senior Researcher of State University of Telecommunications, Kyiv, Ukraine. Research interests: telecommunications. Publications: about 130 scientific publications.

http://orcid.org/0000-0002-7237-4330

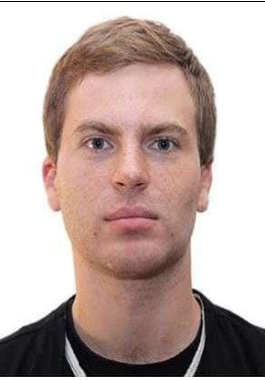

M.Sc. Vyacheslav Parkhomenko

e-mail: viacheslav.p7788@gmail.com

Senior lecturer of the department of

Telecommunications, State University of

Telecommunications, Kyiv, Ukraine. Research interests: telecommunications. Publications: about 23 scientific publications.

http://orcid.org/0000-0002-9120-6842

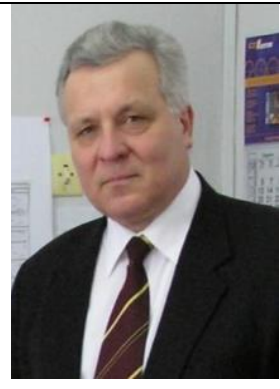

otrzymano/received: 28.02 .2021 